\title{
Fuzzy Assessment of Educational Potential in the Regions of Ukraine
}

\author{
Vasyl Pryimak \\ Faculty of Economics \\ Ivan Franko National University \\ of Lviv \\ Lviv, Ukraine \\ pryimak_vasyl@ukr.net \\ Volodymyr Vovk \\ Faculty of Economics \\ Ivan Franko National University \\ of Lviv \\ Lviv, Ukraine \\ vovk.v.r@gmail.com
}

\author{
Natalia Mishchuk \\ Faculty of Economics \\ Ivan Franko National University \\ of Lviv \\ Lviv, Ukraine \\ mishchuk_n@ukr.net
}

\author{
Stepan Trokhaniak \\ Faculty of Economics \\ Ivan Franko National University \\ of Lviv \\ Lviv, Ukraine \\ s_trokhanyak@ukr.net
}

\begin{abstract}
The paper deals with fuzzy clustering of the regions in Ukraine depending on their level of educational potential development. A hierarchical system of fuzzy logic inference was designed. It models interconnection between the following indicators: the level of human potential development, the level of economic development, the level of development of educational institutions. A fuzzy logic inference has been built using Mamdani algorithm. A base of fuzzy logic output, namely fuzzy knowledge base, along with the system of fuzzy logic equations that provide obtaining numerical values of membership functions and integrated assessment of educational potential was created. The calculations were based on the official statistics in the regions of Ukraine for 2010 and 2017. To automate calculating the models of educational potential assessment Fuzzy Logic Toolbox subsystem of the Matlab application package was used. The obtained results of modeling demonstrate the increase of educational potential almost in all non-occupied territories of Ukraine for the period from 2010 till 2017.
\end{abstract}

Keywords-education, educational potential, fuzzy logic, cluster model, generalized index.

\section{INTRODUCTION}

A prerequisite for the formation of the knowledge economy is the introduction of innovations, the widespread use of new information and communication technologies and the development of education. The new economy needs highly educated workers who could cope with the tasks they face. In order to provide the people a high level of knowledge and competencies, the educational industry should continuously develop, educators and education administrators should seek ways to improve the learning process, methods and approaches to learning and managing them.

Effective management of the education system is possible only in the presence of feedback, if there is information about the state of this system in a certain region or the whole state. Therefore, scientific research on the assessment of the level of education and educational potential of a particular territorial unit is relevant. Taking into account that the procedure of this evaluation relates to weakly structured research tasks, it is expedient to use the fuzzy set theory and data mining technologies in its implementation.

\section{ANALYSIS OF RECENT RESEARCH AND PUBLICATIONS}

Ukrainian scholars Andrushchenko V.P., Boretsky N.O., Hrynkevych O.S., Grishnova O.A., Hubersky N.L., Karzun I.G., Lopushnyak G.S., Rybchanska Kh.V., Topuzov M.O., Filippova V.D., Shestakovska T.L. dedicated their scientific work to the study of the state of education and educational potential in Ukraine, the methods of regulating the development of this sphere and the processes taking place in it. In particular, Hrynkevych O.S. analyzed the peculiarities of the development of higher education in Ukraine and its regions in the context of the goals of sustainable development, integration into the global educational space, formation of a new technological structure. [1]. Hubersky N.L. in her work [2] clarify the goal of state policy in the field of higher education, its objectives and principles. Strategic benchmarks and priorities of the innovative development of the higher education system in Ukraine are defined in the monograph Lopushnyak G.S., Rybchanska Kh.V. [3]. Filippova V.D. considered the specifics of state regulation in the field of education in Ukraine, ensuring the balance of private and public interests of participants in the educational process [4].

Scientists Babiy M.S., Gorban A.N., Klebanova T.S., Matviychuk A.V., Nedosyekin A.A., Panochyshyn Y.M., Rothstein O.P., Syavavko M.S., Shtovba S.D. dedicated their studies to the study of economic phenomena and processes using the apparatus of fuzzy logic. In scientific papers [5,6], the mathematical apparatus of fuzzy sets theory and fuzzy logic, respectively, used to assess the financial stability of banks and to diagnose bankruptcy of enterprises. The monograph [7] reviewed the use of this apparatus to support decision-making in the management of the enterprise. In the scientific paper [8] an algorithm for assessing the knowledge of young people using elements of fuzzy logic is proposed. However, there are no scientific studies on the integrated assessment of the educational potential of the region using the theory of fuzzy logic.

The purpose of this work is to perform using the apparatus of the fuzzy logic of grouping the regions of Ukraine depending on the level of development of their educational potential in 2010 and 2017 and to compare the obtained results. 
To achieve this goal, we had to solve the following tasks:

- to analyze and highlight the main factors contributing to the educational potential of the region;

- to construct a hierarchical system of fuzzy logical conclusion that simulates the relationship between the indicator of the level of development of educational potential and the primary factors;

- to build a base of fuzzy knowledge and fuzzy logic system of equations that provide the obtaining of numerical values of membership functions and integral estimation of educational potential;

- on the basis of official statistics in the regions of Ukraine for 2010 and 2017, using the MATLAB, perform calculations of the educational potential level for each of the specified regions and periods of time;

- to group the regions of Ukraine, depending on the level of educational potential.

\section{THE MAIN MATERIAL}

At the present stage of the economy development, workers are faced with the requirement of a high level of their education. In order to win the competitive struggle in the labor market, able-bodied citizens of our country must be highly educated, creative and critical thinking, be able to work in a team, constantly study, etc. Some of these characteristics directly or indirectly depend on the level of the education sector development in the region or country as a whole. It is impossible to achieve a high level of education in a country with an imperfect sphere of education. That is, the progressive development of the knowledge economy is possible only in a country with a sufficiently high level of educational potential.

Educational potential is a set of available and accumulated educational resources that society has to provide for socio-economic development, and opportunities for their future development through the implementation of rational state policy in the educational sphere. Quantitative parameters of the educational potential are determined by a series of absolute and relative indicators [9].

In order to the rational state policy of the education system, it is necessary to constantly monitor the state of this system, in particular the educational potential of a country or a region. To solve such problems, some scholars are looking for the value of corresponding integral or generalized indicators whose values are calculated using precise algorithms [10]. However, that studied potential is difficult to assess with the help of classical algorithms of economic analysis through the peculiarity of educational activity. This feature consists in the necessity of using both quantitative and qualitative factors to determine the level of the educational potential development of a particular structural unit. The application of classical research methods in this case is too problematic.

In assessing the educational potential of a country or region, we find ourselves in a poorly structured situation in which the use of accurate decision-making methods can lead to significant errors in the results of this assessment. Therefore, in this case there are mathematical methods that would take into account this particular feature of educational activity. These methods include those based on the theory of fuzzy logic and fuzzy sets.

The theory of fuzzy logic was initiated by Lotfi A. Zadeh in the mid-60s of the previous century to overcome the difficulties of presenting inaccurate information. The basis of this theory is the concept of fuzzy set, with the help of which the formalization of such information is carried out. In a classical set theory, the corresponding element belongs to or does not belong to a certain set, however, in the theory of fuzzy sets, some element may belong to a plurality by half, by a quarter, or by another part [11]. To indicate the membership force of an element in a certain set, the corresponding number from the space $[0,1]$ is used.

We used this theory to assess the development level of educational potential in the regions of Ukraine. At the same time, taking into account the fact that the educational potential of the region determines a number of factors, the derivative measurements were used for its estimation. In fact, the value of the fuzzy integral indicator for each of these areas, whose magnitude corresponds to their educational potential, has been found. To automate calculations, the MATLAB Fuzzy Logic Toolbox module was used.

In the beginning, let's consider the factors we have chosen for fuzzy assessment of the potential and justify the association of some of them into the respective groups.

In the process of further calculations, we needed to form the knowledge base [11] for the initial indicator, whose dimension and difficulty of creating it sharply increase with the increase in input factors. Therefore, with a large number of input factors, it is expedient to group them hierarchically and develop knowledge bases for all indicators of each (except the lowest) level of the hierarchy. As a result, a hierarchical system of fuzzy output is obtained, in which the output of the knowledge base of the lower level is fed to the input of the corresponding knowledge base of the higher level of the hierarchy [12].

In our opinion, regions or countries level of the educational potential development $\left(y_{4}\right)$ is determined by such aggregated factors of influence (intermediate aggregate indicators), which, in turn, are determined by the primary factors (in brackets the corresponding notations are indicated):

A. The level of development of human potential of the region $\left(y_{1}\right)$ :

- Economically active people $\left(x_{1}\right)$;

- Employment level in the region $\left(x_{2}\right)$;

- Regional Migration Growth $\left(x_{3}\right)$.

B. The level of economic development of the region $\left(y_{2}\right)$ :

- Gross regional product $\left(x_{4}\right)$;

- Average salary in the region $\left(x_{5}\right)$;

- Consumer price index in the region $\left(x_{6}\right)$.

C. Development level of educational institutions in the region $\left(y_{3}\right)$ :

- The number of higher education institutions in the region $\left(x_{7}\right)$; 
- Number of people admitted to study in the region $\left(x_{8}\right)$;

- The need for workers in the region $\left(x_{9}\right)$.

The primary factors are divided into three groups.

Therefore, there are no difficulties in constructing analytical expressions for functional dependences between the parameters considered by us in the general form. Their graphic representation is shown in Figure 1.

Fuzzy logical conclusion is formed according to the algorithm of Mamdani. To simulate aggregated factors (generalized indicators) $y_{1}, y_{2}, y_{3}$ created fuzzy expert knowledge base containing, respectively, 23, 21 and 27 rules and models for determining the level of educational potential $y_{4}-29$ rules. To implement a clear logical conclusion, the transition from utterances to fuzzy logical equations to knowledge bases of the variables $y_{1}, y_{2}, y_{3}, y_{4}$ is carried out.

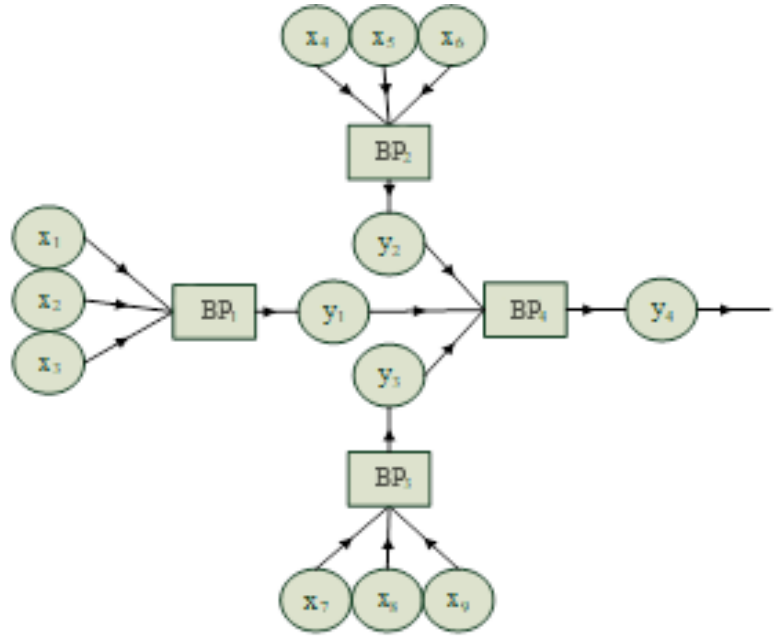

Fig. 1. Hierarchical classification of factors influencing the level of development of educational potential

On the Figure $1 \mathrm{BP}_{i}$ - the basis of fuzzy production rules, that is, fuzzy knowledge bases, for $y_{i}(i=\overline{1,4})$. In the hierarchically related knowledge bases, the initial variable of each knowledge base $\mathrm{BP}_{i}(i=\overline{1,3})$ is the input for the knowledge base of the higher level of the hierarchy $\mathrm{BP}_{4}$.

To analyze the educational potential were selected official statistics of these factors in 2010 and 2017 [13]. Considering the specifics of the input data, in the process of evaluating the level of the educational potential development, when constructing a fuzzy logic output, the trapezoidal membership function and the term set were selected at the phase of phasing, that is, at the transition stage from the clear input variables $X=\left\{x_{i}\right\}, i=\overline{1, n}$ (primary indicators) to fuzzy sets for the corresponding linguistic variables with the following linguistic terms: L - low, M Medium, H - high. For linguistic variables of integral indicators (aggregated factors and output) for the estimation of the level of the educational potential development, a belllike type of membership functions was chosen [11].

The solution of the system of fuzzy logic equations is the fuzzy logical conclusion, that is, the set of membership function values of the output variable. The transition to a clear value is done by means of dephasification by the center of gravity method [11].

As a result of calculations, we obtained the values of integral indices corresponding to the aggregated factors and the initial index, that is, the level of the educational potential development. The most optimistic estimate is 50, the average value is 0 , the value of the most pessimistic evaluation is $(-50)$.

The simulation results showed that the level of human development in the regions of Ukraine increased in 2017 compared to 2010. However, it decreased in Donetsk, Luhansk and Volyn regions.

Simulation results of the level of economic development indicator of the regions of Ukraine in 2010 and 2017 indicate an increase in most regions. The largest increase in the level of economic development was observed in the Volyn region $(+22)$. The decrease in the indicators value occurred only in the following regions: Donetsk (-25), Lugansk (-22), Ternopil (-3) and Chernivtsi (-38). According to the simulation results, the most negative dynamics on the indicator of the development level of the educational institutions network by regions of Ukraine in 2017 are Donetsk (-64) and Lugansk (-34) regions. Mykolaiv (12) and Kharkiv (11) regions indicate the best dynamics.

Regarding the general educational potential, from 2010 to 2017 it decreased only in three regions: Donetsk (-49), Luhansk (-41) and Chernivtsi (-21).

From the results obtained, we can conclude that in 2017, the value of integrated indicators, compared to 2010, increased. An exception to all of these indicators was Donetsk and Luhansk regions, in which the value of calculated indicators decreased. This is due to the fact that in 2017 did not take into account part of the territory of these regions, temporarily occupied by Russia. In addition, in the period from 2010 to 2017, degraded human potential in the Volyn region, and in Ternopil and Chernivtsi - economic development, in Chernivtsi region - the overall educational potential.

Despite the positive dynamics of the indicator, the level of development of educational potential, in almost all regions of Ukraine, both in 2010 and in 2017, was negative.

For a more detailed analysis of the current situation, based on the results of calculating the integral indicator of the educational potential development level, a cluster analysis of Ukrainian regions by the magnitude of this indicator for each of the analyzed years was performed (Table I, II).

In this table, the low level of the educational potential development of the region corresponds to the value of the generalized indicator for the interval $[-50 ;-30]$ low medium $(-30,-10]$ medium - $(-10,10]$ high medium - $(10 ; 30]$ and high - $(30 ; 50]$.

As can be seen from this table, the largest areas (8-10) form the second and third clusters, that is, in 2010, of the educational potential development level, respectively, in the 8 and 10 regions of Ukraine is lower than the average and the average, and in 2017 both these clusters consist of 9 oblasts. The least regions (one in each of these years) refers to the last cluster with a high value of this aggregate indicator. 
TABLE I. CLUSTERS OF UKRAINIAN REGIONS ACCORDING TO THE EDUCATIONAL POTENTIAL DEVELOPMENT LEVEL IN 2010

\begin{tabular}{|c|c|c|}
\hline \multirow{2}{*}{$\begin{array}{c}\text { Cluster } \\
\text { (level) }\end{array}$} & \multicolumn{2}{|c|}{2010} \\
\hline & Region & Rating \\
\hline \multirow{3}{*}{ Low } & Volyn & -40 \\
\hline & Ternopil & -42 \\
\hline & Kherson & -36 \\
\hline \multirow{8}{*}{$\begin{array}{c}\text { Low } \\
\text { medium }\end{array}$} & Zhytomyr & -10 \\
\hline & Zakarpattia & -14 \\
\hline & Ivano-Frankivsk & -13 \\
\hline & Kirovohrad & -20 \\
\hline & Rivne & -16 \\
\hline & Sumy & -15 \\
\hline & Khmelnytsky & -12 \\
\hline & Chernihiv & -28 \\
\hline \multirow{10}{*}{ Medium } & Vinnytsia & -5 \\
\hline & Zaporizhia & 0 \\
\hline & Kyiv & 7 \\
\hline & Lugansk & 0 \\
\hline & Lviv & 8 \\
\hline & Mykolaiv & -8 \\
\hline & Odesa & 0 \\
\hline & Poltava & 0 \\
\hline & Cherkassy & -9 \\
\hline & Chernivtsi & -6 \\
\hline \multirow{2}{*}{$\begin{array}{c}\text { High } \\
\text { medium }\end{array}$} & Dnipropetrovsk & 27 \\
\hline & Kharkiv & 14 \\
\hline High & Donetsk & 42 \\
\hline
\end{tabular}

TABLE II. CLUSTERS OF UKRAINIAN REGIONS ACCORDING TO THE EDUCATIONAL POTENTIAL DEVELOPMENT LEVEL IN 2017

\begin{tabular}{|c|c|c|}
\hline \multirow{2}{*}{$\begin{array}{c}\text { Cluster } \\
\text { (level) }\end{array}$} & \multicolumn{2}{|c|}{2017} \\
\hline & Region & Rating \\
\hline \multirow{2}{*}{ Low } & Volyn & -39 \\
\hline & Lugansk & -41 \\
\hline \multirow{9}{*}{$\begin{array}{c}\text { Low } \\
\text { medium }\end{array}$} & Zakarpattya & -12 \\
\hline & Kirovohrad & -18 \\
\hline & Rivne & -13 \\
\hline & Sumy & -11 \\
\hline & Ternopil & -19 \\
\hline & Kherson & -15 \\
\hline & Khmelnitsky & -10 \\
\hline & Chernivtsi & -27 \\
\hline & Chernihiv & -23 \\
\hline \multirow{9}{*}{ Medium } & Vinnytsia & 0 \\
\hline & Donetsk & -7 \\
\hline & Zhytomyr & -6 \\
\hline & Zaporizhia & 0 \\
\hline & Ivano-Frankivsk & -8 \\
\hline & Mykolaiv & -7 \\
\hline & Odesa & 5 \\
\hline & Poltava & 0 \\
\hline & Cherkassy & -9 \\
\hline \multirow{3}{*}{$\begin{array}{l}\text { High } \\
\text { medium }\end{array}$} & Kyiv & 18 \\
\hline & Lviv & 11 \\
\hline & Kharkiv & 25 \\
\hline High & Dnipropetrovsk & 40 \\
\hline
\end{tabular}

The results of the performed cluster analysis show that in the period from 2010 to 2017 , the educational potential in Ukraine and its regions has improved significantly. Nearly all regions in 2017 remained in the same cluster or moved to a cluster with the best level of the educational potential development compared to 2010. The only exception was Donetsk, Lugansk and Chernivtsi regions. This is a consequence of the significant political and social changes that have taken place in Ukraine. During this period in Ukraine, due to the loss of territories, the restructuring of the national economy, the reorientation of export-import markets, and significant migration processes took place. All this influenced the country's educational potential.

\section{CONCLUSIONS}

Thus, our research has shown that the theory of fuzzy logic and fuzzy sets can be effectively used to determine the educational potential development level of the region. The proposed hierarchical model of complex evaluation of educational potential not only allows to calculate its value, but also analyze its various components according to the components of the model (groups of indicators). The model is easy to modify, complementing it with new factors or replacing one with the other, which is convenient for users, taking into account the variability of the market environment.

The results of the fuzzy evaluation of the educational potential development level of Ukrainian regions and their cluster analysis showed that in the period from 2010 to 2017 , educational potential has slightly improved in almost all its regions and in Ukraine in general. During this period in Donetsk, Lugansk and Chernivtsi regions not only degraded the educational potential, but also, in terms of their development, they moved to the worst cluster.

\section{REFERENCES}

[1] O.S. Hrynkevych, Competitiveness Governance of Ukraine's Higher Education: Institutional Analysis and Monitoring, L'viv: Ivan Franko National University of L'viv, 2018.

[2] N.L. Guberska "The purpose, objectives and principles of state policy in Ukraine system of higher education", Kherson State University Herald. Series "Legal Sciences", no 3, vol. 2, pp. 158-162, 2014

[3] G. Lopushnyak, and C. Rybchanska, Higher education in Ukraine: state regulation and development prospects: Monograph. K.: DNDIIME, 2018.

[4] V. Filippova, Specific of government control in the area of education of formation of Ukraine. Theoretical and applied issues of state building. 2013, Iss. $12 . \quad$ [Online]. Available: http://nbuv.gov.ua/UJRN/tppd_2013 12 12. Accessed on: 12 June 2019.

[5] Y.N. Panochyshyn, and K.Y. Rumiantseva "The using of mathematical apparatus of fuzzy sets and fuzzy logic theory in the task of business solvency estimation of commercial banks," Visnyk of Zaporizhzhya National University, no 2, pp. 80-86, 2011.

[6] A.V. Matviychuk, "Fuzzy, neural network and discriminant models for diagnosing the possibility of bankruptcy of enterprises," Neurofuzzy simulation technologies in the economy, vol. 2, pp.71-118, 2013.

[7] T. Klebanova, L. Chagovets, and O. Panasenko, Fuzzy Logic And Neutral Networks In Enterprise Management: monograph. Kharkiv: Inzhek, 2011.

[8] M.S. Babiy, and A.P. Checalov "Application of fuzzy logic elements for rating system of knowledge assessment". Visnyk SumDU. Series "Technical Scineces", no 3, pp. 116-121, 2011.

[9] Economic Dictionary. [Online]. Available: https://predmety.in.ua/osvitnij-potencial/. Accessed on: 10 June 2019

[10] P.M. Hryhoruk, and N.A. Khrushch "Complex assessment of the level and dynamics of innovative capacity of region. Marketing and Management of Innovations", no 3, pp. 109-129, 2016.

[11] M.S. Syavalko, Intellectual information system "Fuzzy Expert". Publishing Center of Ivan Franko National University of LNU, 2007.

[12] S.D. Shtovba, and A.V. Nagorna "Logic selection under the ieraric hybrid non-channel knowledge bases,": in Proceedings of the Second International Conference on Computational Intelligence (Results, Problems and Perspectives), Cherkasy, 2013, pp. 128-131.

[13] State Statistics Service of Ukraine. [Online]. Available: http://www.ukrstat.gov.ua). Accessed on: 10 June 2019. 